\title{
GMR
}

\section{Fermentation of Foc TR4-infected bananas and Trichoderma spp}

\author{
J. Yang ${ }^{1 *}$, B. Li ${ }^{1 *}$, S.W. Liu ${ }^{1 *}$, M.K. Biswas ${ }^{2,3}$, S. Liu ${ }^{4}$, Y.R. Wei ${ }^{2,3}$, \\ C.W. Zuo ${ }^{2,3}$, G.M. Deng ${ }^{2,3}$, R.B. Kuang ${ }^{2,3}$, C.H. Hu ${ }^{2,3}$, G.J. Yi ${ }^{2,3}$ and C.Y. Li ${ }^{2,3}$ \\ ${ }^{1}$ The College of Life Sciences, South China Agricultural University, \\ Guangzhou, China \\ ${ }^{2}$ Institution of Fruit Tree Research, \\ Guangdong Academy of Agricultural Sciences, Guangzhou, China \\ ${ }^{3}$ Key Laboratory of South Subtropical Fruit Biology and Genetic Resource \\ Utilization, Ministry of Agriculture, Guangzhou, China \\ ${ }^{4}$ The College of Horticulture, Shenyang Agricultural University, Shenyang, China \\ *These authors contributed equally to this study. \\ Corresponding authors: G.J. Yi / C.Y. Li \\ E-mail: yiganjun@vip.163.com / lichunyu881@163.com
}

Genet. Mol. Res. 15 (4): gmr15048494

Received January 26, 2016

Accepted June 15, 2016

Published October 17, 2016

DOI http://dx.doi.org/10.4238/gmr15048494

Copyright (C) 2016 The Authors. This is an open-access article distributed under the terms of the Creative Commons Attribution ShareAlike (CC BY-SA) 4.0 License.

\begin{abstract}
Fusarium wilt (also known as Panama disease) is one of the most destructive banana diseases, and greatly hampers the global production of bananas. Consequently, it has been very detrimental to the Chinese banana industry. An infected plant is one of the major causes of the spread of Fusarium wilt to nearby regions. It is essential to develop an efficient and environmentally sustainable disease control method to restrict the spread of Fusarium wilt. We isolated Trichoderma spp from the rhizosphere soil, roots, and pseudostems of banana plants that showed Fusarium wilt symptoms in the infected areas. Their cellulase activities were measured by endoglucanase activity,
\end{abstract}


$\beta$-glucosidase activity, and filter paper activity assays. Safety analyses of the Trichoderma isolates were conducted by inoculating them into banana plantlets. The antagonistic effects of the Trichoderma spp on the Fusarium pathogen Foc tropical Race 4 (Foc TR4) were tested by the dual culture technique. Four isolates that had high cellulase activity, no observable pathogenicity to banana plants, and high antagonistic capability were identified. The isolates were used to biodegrade diseased banana plants infected with GFP-tagged Foc TR4, and the compost was tested for biological control of the infectious agent; the results showed that the fermentation suppressed the incidence of wilt and killed the pathogen. This study indicates that Trichoderma isolates have the potential to eliminate the transmission of Foc TR4, and may be developed into an environmentally sustainable treatment for controlling Fusarium wilt in banana plants.

Key words: Banana; Trichoderma; Foc TR4; Fusarium wilt; Biodegradation; Disease control

\section{INTRODUCTION}

Fusarium wilt is one of the most notorious diseases that affect banana plants, and it is caused by the soil-borne hyphomycete, Fusarium oxysporum f. sp cubense (Foc) (Ploetz, 2015). Based on the its virulence in specific banana cultivars (Ploetz, 1990,1994), the pathogen can be classified into three races: 1, 2 and 4. In the 1950s, exports of Gros Michel bananas from Central America to North America and Europe were dramatically reduced owing to Foc Race 1 infection (Ploetz, 1994). Foc subtropical Race 4 has reduced the production area of Taiwan from 50,000 to 5000 ha in the last 10 years (Hwang and Ko, 2004); Foc tropical Race 4 (TR4) is the most virulent strain of $F o c$, and is presently sweeping through banana plantations in Asia. It has become a major threat to the banana industry (Li et al., 2012). The disease has changed the geographical distribution of banana-growing districts in mainland China. Ten years ago, more than $50 \%$ of Chinese banana output was from Guangdong Province, but that has now been reduced to approximately $20 \%$; the growing area has decreased from 140,000 to 70,000 ha, and now ranks third after Guangxi and Yunnan provinces. The incidence of disease in Guangdong Province now ranges between 20 and $40 \%$, with individual plantations reaching $90 \%$ (Huang et al., 2012). Without effective inspection and quarantine measures, this disease has spread rapidly to new growing areas.

To control the spread of Foc TR4, the routes of transmission must be eliminated. Infected plants transmit disease through soil, air, and flowing water. Once the spore contacts the host plant it germinates and penetrates the plant tissue, producing abundant microconidia in the xylem vessels; these move to other plant organs through the vascular system, culminating in systemic colonization of that system (Beckman, 1990). Ideally, severely affected plants should be uprooted and incinerated. In a production scenario, incineration is unfeasible owing to the huge amounts of diseased biomass in the infected areas. Burning the banana plants also results in the loss of nutrients and causes air pollution.

An environmentally sound, safe, and efficient method for processing diseased plants is urgently needed. In this study, we aimed to: 1) screen Trichoderma species found in the

Genetics and Molecular Research 15 (4): gmr15048494 
rhizosphere soil, roots, and pseudostems of banana plants for high cellulase activity, 2) use the Trichoderma isolates to ferment the diseased plants, and 3) determine the biocontrol capabilities of those isolates through inactivation of the pathogen in a greenhouse.

\section{MATERIAL AND METHODS}

\section{Isolation and identification of Trichoderma spp}

Trichoderma spp were isolated from the rhizosphere soil, roots, and pseudostems of banana plants that showed symptoms of Fusarium wilt, collected from fields in Dongguan, Guangzhou, and Zhongshan, China. The Trichoderma spp were isolated from soil samples by a serial dilution technique using Trichoderma-selective medium. The root and pseudostem samples were processed for the isolation of endophytic Trichoderma according to the protocol described by Mysore et al. (2005).

\section{Testing antagonism of Trichoderma spp against Foc TR4}

A dual culture technique was performed as described by Morton and Stroube (Morton and Stroube, 1955; Joshi et al., 2010). Discs (4 cm in diameter) were cut from the growth media of Trichoderma spp and Foc TR4 using a cork borer and were placed separately on potato dextrose agar (PDA) (Shenggong, Shanghai, China) medium $1 \mathrm{~cm}$ from the edge of the plate. Three replicate plates for each treatment were maintained. Percent inhibition over control was calculated using the following formula (Joshi et al., 2010):

$$
\mathrm{I}=(\mathrm{C}-\mathrm{T}) \times 100 \% / \mathrm{C}
$$

where $\mathrm{I}=$ percent inhibition in mycelia growth, $\mathrm{C}=$ growth of pathogen on control plates, and $\mathrm{T}=$ growth of pathogen on dual culture plates.

\section{Measurement of enzyme activity}

Filter paper activity assays were performed to determine the total cellulase activity of each Trichoderma isolate according to the method described by Ghose (1987). Trichoderma isolates were cultured and filtered to prepare appropriate dilutions to provide the enzyme source. Dilute culture $(0.5 \mathrm{~mL})$ was mixed with $1 \mathrm{~mL}$ citrate buffer $(0.1 \mathrm{M}, \mathrm{pH} 4.8)$, and $50 \mathrm{mg}$ Whatman No. 1 filter paper $\left(1 \times 6 \mathrm{~cm}\right.$ strip) and incubated at $50^{\circ} \mathrm{C}$ for $1 \mathrm{~h}$. The amount of reducing sugar released from the filter paper was determined by the 3,5-dinitrosalicylic acid (DNS) method (Miller, 1959). One unit of filter paper activity was defined as the amount of enzyme releasing 1 mmol reducing sugar from filter paper per $\mathrm{mL}$ per min (Gautam et al., 2012).

Endoglucanase activity was measured using a reaction mixture containing $1 \%$ carboxymethyl cellulose $(1 \mathrm{~mL})$ in $0.05 \mathrm{M}$ sodium citrate buffer, $\mathrm{pH} 4.8$, and aliquots of the diluted culture filtrate; the quantity of reducing sugar produced was determined by the DNS method (Miller, 1959). $\beta$-glucosidase activity was assayed using the protocol described by Pointing et al. (1999). One unit of enzyme activity was defined as the amount of enzyme releasing $1 \mathrm{mmol}$ reducing sugar per min.

Genetics and Molecular Research 15 (4): gmr15048494 


\section{Safety analysis of the Trichoderma isolates on banana plantlets}

PDA Petri plates containing the Trichoderma isolates and Foc TR4 were incubated at $28^{\circ} \mathrm{C}$ until they were well sporulated, and were then stored at $4^{\circ} \mathrm{C}$. The spores were harvested by washing the Petri plates with $50 \mathrm{~mL}$ double-distilled water ( $\mathrm{ddH}_{2} \mathrm{O}$ ) containing $0.1 \%$ Tween-80 (Sigma-Aldrich). The spore concentration was determined in a counting chamber and the inoculum concentration was adjusted to $1.0 \times 10^{6} \mathrm{CFU} / \mathrm{mL}$. We applied a modified version of the stab-inoculation method described by Haygood and Strider (1982). Brazilian banana plantlets (Musa AAA Cavendish) were produced by tissue culture in our group facility, and plantlets with four or five leaves were selected for the inoculation studies. The spores (5.0 $\mu \mathrm{L}$ ) were stab-inoculated into the wounded pseudostems; water and Foc TR4 spores served as the negative and positive controls, respectively.

\section{Fungal identification}

Trichoderma isolates with high cellulase activity, no observable pathogenicity to banana plants, and high antagonistic capacity were identified according to the protocol developed by Castle et al. (1998). Colony appearance and sporulation patterns were recorded from cultures grown on PDA or cornmeal dextrose agar at $25^{\circ} \mathrm{C}$ in darkness. Morphological characteristics were recorded under a Zeiss Axiophot 2 microscope with an Axiocam CCD camera and Axiovision digital imaging software (Axiovision Software Release 3.1., v.3-2002; Carl Zeiss Vision Imaging System).

The DNA of four Trichoderma isolates was extracted using an E5038 plant/fungus DNA isolation kit (Sigma). Genomic regions of the three genes, i.e., translation-elongation factor 1 alpha (tef1), RNA polymerase II subunit B ( rpb2), and ATP citrate lyase (acl1) were amplified following the procedure described by Jaklitsch et al. (2013), and the polymerase chain reaction products were extracted from $1.5 \%$ agarose gel and sequenced by the Beijing Genomics Institute. Subsequently, sequences (tef1, rpb2, and acl1) were BLASTed against the National Center for Biotechnology Information (NCBI) database, using the default parameter. Thirty-five homologous sequences were downloaded from the different Trichoderma spp based on high sequence similarity. All 35 homologs and the four reference sequences from each gene were aligned separately using the Molecular Evolutionary Genetics Analysis Version 6.0 (MEGA6) software and manually trimmed. The trimmed sequences of each gene were then joined together using an ad hoc perl script written inhouse. The homologs and reference sequences were then aligned again with MEGA6 using the default parameter (Tamura et al., 2013). A neighbor-joining bootstrap phylogeny tree was constructed using the default parameter, and the bootstrap replication number was 1000 .

Single-spore cultures of the identified Trichoderma isolates were frozen at $-80^{\circ} \mathrm{C}$ in $50 \%$ glycerol, and are archived in the Agricultural Culture Collection of China in the Chinese Academy of Agricultural Sciences, Beijing.

\section{Biodegradation of the diseased banana plants and bioassays}

\section{Initial cultivation of Trichoderma isolates}

The defined initial cultivation medium contained $70 \%$ dried and milled banana

Genetics and Molecular Research 15 (4): gmr15048494 
stalks, $30 \%$ wheat bran, $2 \%$ ammonium sulfate solution $\left(100 \mathrm{~mL}\right.$ with $0.1 \mathrm{~g} \mathrm{KH}_{2} \mathrm{PO}_{4}$ and $0.05 \mathrm{~g} \mathrm{MgSO}_{4} \cdot 7 \mathrm{H}_{2} \mathrm{O}$ ); the media was autoclaved at $121^{\circ} \mathrm{C}$ for $20 \mathrm{~min}$ and cooled. The spore suspensions of the Trichoderma isolates with high cellulolytic activity were inoculated at a rate of $10^{6}$ spores $/ \mathrm{g}$ medium, and incubated for 10 days at $28^{\circ} \mathrm{C}$.

\section{Small-scale fermentation and greenhouse test}

A green fluorescent protein (GFP)-tagged Foc TR4 spore suspension was prepared as described previously. The artificial inoculation of banana plants for small-scale fermentation and biocontrol testing in a greenhouse has been described previously (Li et al., 2011), except that the spore concentration in the soil was increased to 10,000 conidia/g soil and 400 Brazilian banana plants (Musa spp, AAA-group) with 10-12 leaves were inoculated. After 1 month, the diseased banana plants were harvested and cut into pieces; they were then mixed with equal amounts of rice straw and 1\% Trichoderma complex for fermentation. The composting materials were covered with plastic films and fermented for 30 days. After fermentation, the samples were examined by fluorescence microscopy (Li et al., 2011) and incubated in PDA medium to assay for pathogen survival.

The fermented composts were tested for biocontrol of the pathogenic agent. The soil (Li et al., 2011) was autoclaved and mixed with $20 \%$ of the fermented compost; the GFPtagged Foc TR4 spores were then added to the soil to a final concentration of 2000 spores $/ \mathrm{g}$ soil. Two controls were used: the positive control contained soil and fermentation product without the inoculated pathogen, whereas the negative control contained the pathogen in the soil and no fermentation product. After plantlets with 5-6 leaves had been transplanted, the pots were maintained in the greenhouse at $\sim 30^{\circ} \mathrm{C}$ for 30 days. The plants were then removed from the soil and the roots were washed with sterile distilled water. The roots were excised from the plants and the data were collected for analysis.

\section{RESULTS}

\section{Screening strains of Trichoderma spp}

The potential use of Trichoderma species as biocontrol agents against crop diseases caused by Fusarium has been reported (Sivan et al., 1987; Sundaramoorthy and Balabaskar, 2013). In the present investigation, 221, 45, and 9 strains of Trichoderma spp were isolated from the rhizosphere soil, roots, and pseudostems of banana plants, respectively. Of the isolates tested, four strains (TM1, 2, 3, and 4) were selected for further research including biofermentation and biocontrol tests in the greenhouse, owing to their strong antagonistic effect on Foc TR4 (Table 1 and Figure 1), high cellulolytic activity, and absence of disease symptoms on the stab-inoculated pseudostems of banana plantlets (Table 1 and Figure 2). The four isolates were characterized by their conidiophores, phialide phenotypes (among others), and the results of phylogenetic analysis, and they were determined to be Trichoderma polysporum, T. longipile, T. viride, and T. harzianum (Table 1 and Figure 3).

Genetics and Molecular Research 15 (4): gmr15048494 
Table 1. Characteristics of the four Trichoderma isolates.

\begin{tabular}{|c|c|c|c|c|c|}
\hline \multicolumn{2}{|l|}{$\begin{array}{l}\text { Items } \\
\end{array}$} & TM1 & TM2 & TM3 & TM4 \\
\hline \multicolumn{2}{|l|}{ Source } & Root & Soil & Soil & Soil \\
\hline \multirow[t]{3}{*}{ Conidiophores } & Length $(\mu \mathrm{m})$ & $2.7-3.8$ & $3.9-6.9$ & $3.3-4.2$ & $2.2-3.8$ \\
\hline & Width $(\mu \mathrm{m})$ & $1.4-2.3$ & $2.8-4.5$ & $3.1-3.8$ & $2.4-3.3$ \\
\hline & $\mathrm{R} 1$ & $1.2-2.0$ & $1.0-1.6$ & $1.0-1.3$ & $1.0-1.5$ \\
\hline \multirow[t]{4}{*}{ Phialides } & Length $(\mu \mathrm{m})$ & $3.9-6.2$ & $8.4-18.1$ & $5.9-11.4$ & $5.6-9.4$ \\
\hline & Maximum width $(\mu \mathrm{m})$ & $3.1-3.8$ & $3.0-3.5$ & $2.1-3.4$ & $2.5-3.4$ \\
\hline & Base width & $2.0-2.9$ & $1.7-2.8$ & $1.0-2.8$ & $1.6-2.8$ \\
\hline & R2 & $1.2-1.9$ & $2.3-5.1$ & $1.9-3.9$ & $1.5-2.2$ \\
\hline Colony color & & White & Green-yellow & Green-yellow & Green \\
\hline Rate of inhibition & & $64.56 \%$ & $58.54 \%$ & $60.52 \%$ & $70.68 \%$ \\
\hline \multirow[t]{3}{*}{ Enzyme activity (IU/mL) } & Exoglucanase & $2.16 \pm 0.05$ & $1.76 \pm 0.04$ & $2.05 \pm 0.05$ & $1.66 \pm 0.04$ \\
\hline & Endoglucanase & $2.01 \pm 0.04$ & $1.78 \pm 0.08$ & $1.79 \pm 0.06$ & $1.46 \pm 0.04$ \\
\hline & $\beta$-glucosidase & $1.93 \pm 0.03$ & $1.69 \pm 0.03$ & $1.96 \pm 0.09$ & $1.42 \pm 0.06$ \\
\hline
\end{tabular}

R1: length/width. R2: length/maximum width. TM: Trichoderma.
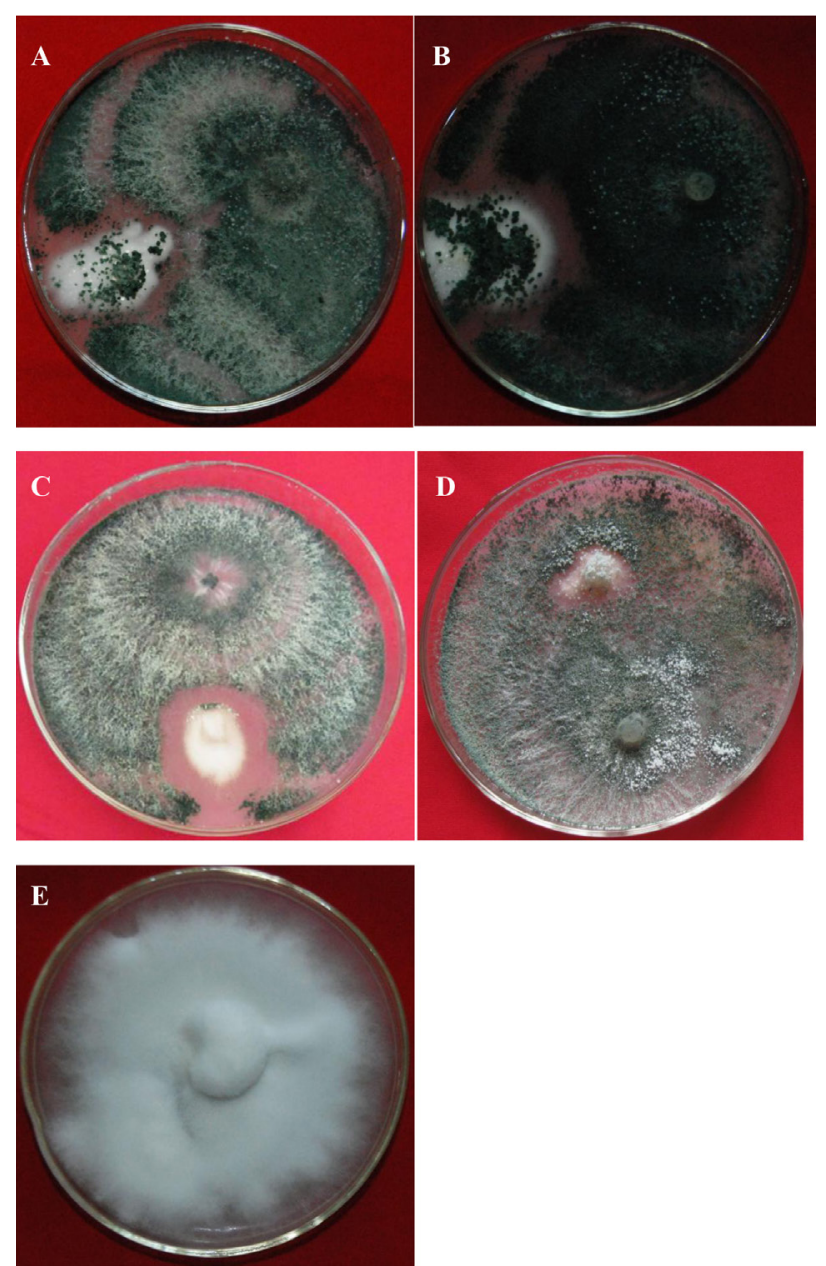

Figure 1. Antagonistic efficacy of Trichoderma spp against Foc TR4 under in vitro conditions. A. TM1; B. TM2; C. TM3; D. TM4; E. Foc TR4.

Genetics and Molecular Research 15 (4): gmr15048494 


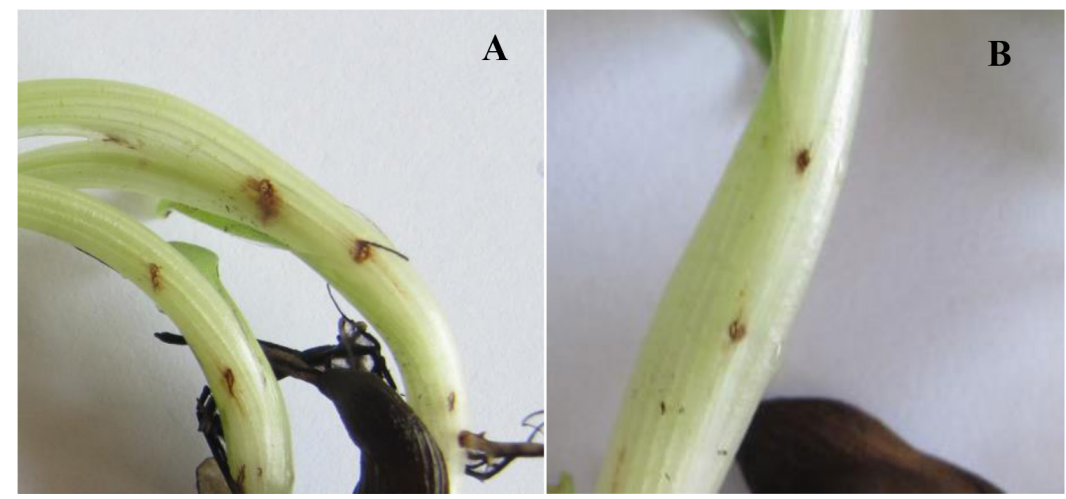

Figure 2. Safety analysis of the Trichoderma isolates on banana plantlets. A. Pathogenic Trichoderma isolates showed spreading disease symptoms; B. biocontrol Trichoderma isolates and water showed the symptoms of programmed cell death.

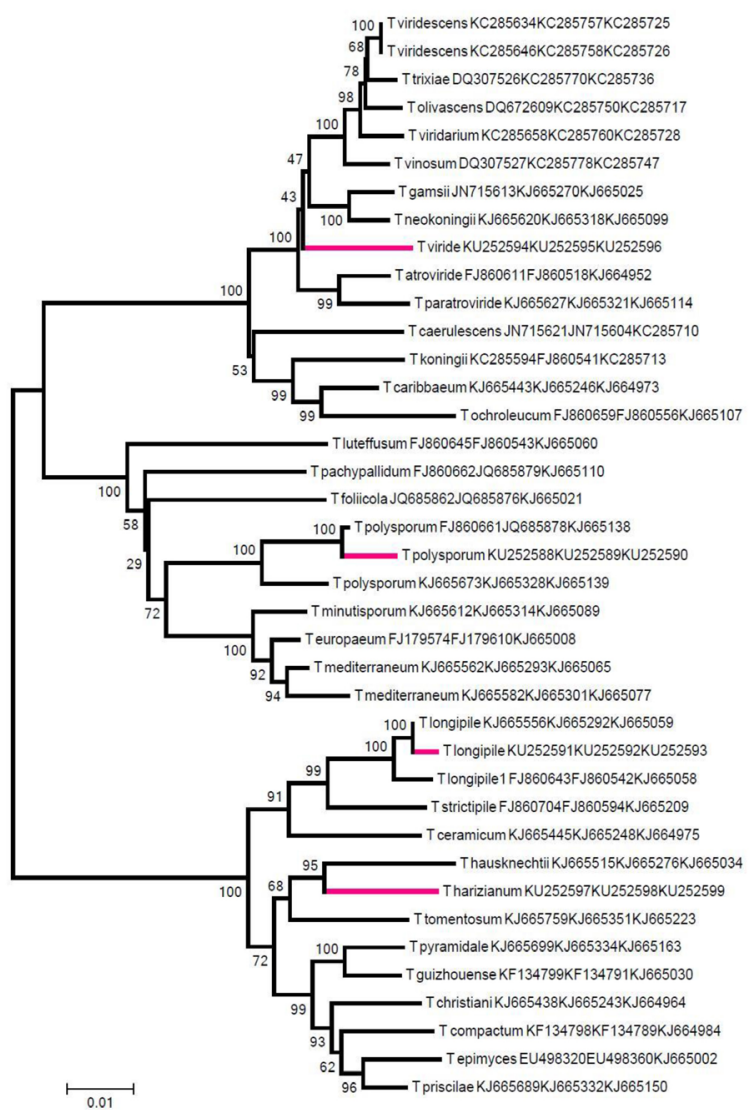

Figure 3. A phylogenetic tree based on combined tef1, rpb2, and acll sequences. Bootstrap values $\geq 50 \%$ are shown above or below branches. Each taxon contains the isolate name and the GenBank accession No. (tefl, rpb2, and $a c l 1)$; the four identified Trichoderma isolates are marked in red.

Genetics and Molecular Research 15 (4): gmr15048494 


\section{Small-scale fermentation}

The GFP-tagged Foc TR4 isolate invaded the susceptible Cavendish banana cultivar and after 1 month the plants showed the characteristics of Fusarium wilt disease, including root rot, yellow leaves, and vascular discoloration. Confocal laser scanning microscopy of banana pseudostems on day 30 showed considerable colonization by the GFP-tagged Foc TR 4 isolate, with fungal hyphae and spores covering large sections of the vascular tissue (Figure 4).

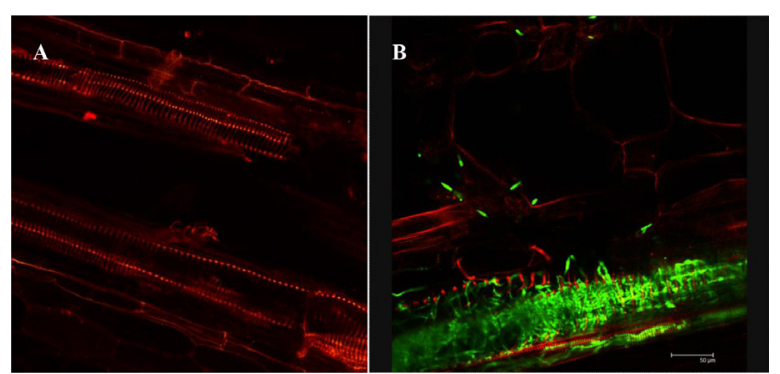

Figure 4. Invasion of green fluorescent protein (GFP)-tagged Foc TR4 isolate in susceptible banana vascular tissues. A. Healthy vascular tissues without Foc TR4; B. fungal hyphae and spores inside banana vascular tissues.

All four Trichoderma isolates grew very well in the initial cultivation medium. After 10 days, we tested the concentration of spores in the initial fermentation, which was at least $10^{9} \mathrm{CFU}$ in all cases. These initial fermentation cultures were mixed in equal amounts. The chopped banana pseudostems and leaves (without any dry processing) were mixed with the Trichoderma complex described above and rice straw, and were fermented for 30 days. After 3 days of fermentation, a large amount of stem sap flowed out; the control, which consisted of chopped banana pseudostems and rice straw without the Trichoderma complex, did not exhibit this phenomenon (Figure 5). The temperature of the Trichoderma treatment gradually increased throughout the process of fermentation, and the highest temperature inside the compost $\left(50^{\circ} \mathrm{C}\right)$ was reached after 20 days. After 30 days, the compost cooled to ambient temperature. The control reached a maximum temperature of only $35^{\circ} \mathrm{C}$ after 25 days.
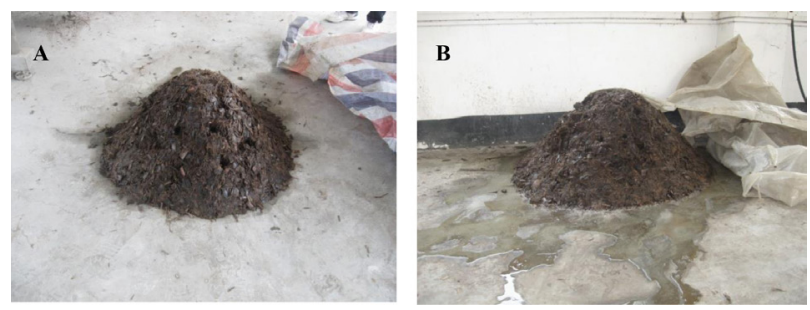

Figure 5. Compost of banana pseudostems and leaves with Trichoderma isolates and the control. A. Control; B. compost of banana pseudostems and leaves fermented with the Trichoderma isolates.

After 30 days of fermentation, we could not discern the clear cell structure of the composted materials and the GFP-tagged Foc TR4 spores in the Trichoderma treatment. The GFP-tagged spores were found in the solution of $\mathrm{ddH}_{2} \mathrm{O}$ soaking the compost materials of the control, and many GFP-tagged Foc TR4 clones were obtained when inoculating back to the PDA medium; we were unable to isolate clones by inoculating the fermented Trichoderma

Genetics and Molecular Research 15 (4): gmr15048494 
treatment, which indicates that the Trichoderma with high cellulolytic activity destroyed the cell structures and killed the pathogen.

We altered the fermentation conditions and investigated their efficiency by adding the four Trichoderma isolates to the compost individually; when compared with the complex mixture, their fermentation rates decreased, suggesting that different mechanisms were taking place and that a synergistic effect was involved in the process. Removal of the rice straw from the compost not only slowed the fermentation rates, but also resulted in a marked decrease in the number of Trichoderma spores; this indicates that rice straw could improve Trichoderma propagation and accelerate its colonization.

\section{Bioassay}

Application of the Trichoderma compost to the soil was effective in reducing the occurrence of Fusarium wilt in banana plants by 30.08-63.91\% (Table 2). All the single Trichoderma composts TM1, 2, 3, and 4 decreased the incidence of wilt by 51.18, 37.66, 30.08 , and $45.51 \%$, respectively; notably, adding the complex Trichoderma compost to the soil decreased the incidence of wilt by $63.91 \%$, which suggests that it had a synergistic effect in suppressing the invasion of Foc TR4, and a combination of several strains with different biocontrol mechanisms might be exploited in sustainable disease management programs.

\begin{tabular}{|c|c|c|c|}
\hline Trt. No. & Fungal antagonists & Plant height $(\mathrm{cm})^{*}$ & Percent disease incidence* \\
\hline 1 & TM1 compost & $14.18^{\mathrm{a}}$ & $25.27^{d}$ \\
\hline 2 & TM2 compost & $11.59^{\mathrm{b}}$ & $38.79^{\mathrm{e}}$ \\
\hline 3 & TM3 compost & $11.06^{\mathrm{c}}$ & $46.37^{\mathrm{f}}$ \\
\hline 4 & TM4 compost & $11.47^{b}$ & $30.94^{\mathrm{d}}$ \\
\hline 5 & Complex compost & $13.94^{\mathrm{a}}$ & $12.54^{\mathrm{c}}$ \\
\hline 6 & Negative control1 & $10.35^{\mathrm{d}}$ & $76.45^{\mathrm{h}}$ \\
\hline 7 & Negative control2 & $10.22^{\mathrm{d}}$ & $64.38^{\mathrm{g}}$ \\
\hline 8 & Positive control & $11.36^{\mathrm{b}}$ & $0^{\mathrm{a}}$ \\
\hline 9 & Complex control & $14.02^{\mathrm{a}}$ & $0^{\mathrm{a}}$ \\
\hline 10 & TM1 control & $14.39^{\mathrm{a}}$ & $0^{\mathrm{a}}$ \\
\hline 11 & TM2 control & $11.43^{\mathrm{b}}$ & $5.12^{\mathrm{b}}$ \\
\hline 12 & TM3 control & $11.21^{\mathrm{b}}$ & $10.16^{\mathrm{c}}$ \\
\hline 13 & TM4 control & $11.33^{\mathrm{b}}$ & $5.62^{\mathrm{b}}$ \\
\hline
\end{tabular}

* Mean of three replications. The same letters in the same column were not significantly different at $\mathrm{P}<0.01$ by the Duncan multiple range test. TM1, 2, 3, 4, and complex control: only compost and without pathogen inoculated into the soil.

Positive control: the natural compost of pieced banana pesodostems and rice straw, without the Trichoderma isolates and Foc TR4. Negative control 1and 2: the natural compost of pieced banana pesodostems and rice straw, without the Trichoderma isolates, inoculated with Foc TR4 in the soil.

The results of this experiment also revealed that the application of fermentation products from TM1 and the complex antagonistic fungal formulations significantly increased banana plant height when compared with those from other isolates of Trichoderma and both controls (Table 2). Because TM1 was isolated from banana plant roots, we can deduce that endophytic fungi promoted plant growth. Although we have not yet investigated the mechanism

Genetics and Molecular Research 15 (4): gmr15048494 
of plant growth promotion, it may be associated with the secretion of auxins, gibberellins, and cytokinins (Waqas et al., 2012).

The pot experiments showed that upon treatment with TM1 and complex Trichoderma composts, the FOC incidence rate was 0 , which suggests that both treatments completely killed the pathogen within the fermentation materials; this was consistent with our confocal microscopy observations. A few diseased plants with wilt symptoms were found in the three other Trichoderma compost treatments; however, the incidence was very low compared with the negative control (Table 2). The only difference between the treatment and control was the presence of Trichoderma isolates in the fermentation compost, which suggests that most of the pathogen spores were killed by fermentation with the other Trichoderma isolates; the GFPtagged Foc TR4 was undetectable by confocal microscopy.

\section{DISCUSSION}

In this study, the four fungal antagonist isolates, particularly the complex, had high cellulolytic activity and biomass conversion rates. All the Trichoderma isolates (particularly the complex formulation) had excellent biocontrol capabilities, and could be used to safely process the great mass of diseased plants in a field setting. However, fermentation of banana pseudostems in the field using the Trichoderma isolates described above is time-consuming, which is a disadvantage for farmers. Our next research objective will be to speed up this fermentation process (Zhang and Yang, 2015), improve the inoculum application method, conduct co-inoculation with different microbial strains, and determine how those modifications affect the biological control of Fusarium wilt (Raza et al., 2016).

\section{Conflicts of interest}

The authors declare no conflict of interest.

\section{ACKNOWLEDGMENTS}

Research supported by the National Natural Science Fund (\#U1131004 and \#31471740), the National Banana Industry and Technology System Project (nycytx-33), the International Collaborative Project (\#2013J4500033, \#2011B050400004, and \#2013DFB30400), the Science and Technology Project of Guangdong Province (\#2013A061402005 and \#2010B031800012), the National Spark Program Project (\#2010GA780005), and the "948" Project of the Department of Agriculture (\#2011-G16). The funding organizations had no role in the study design, data collection, analysis, decision to publish, or preparation of the manuscript.

\section{REFERENCES}

Beckman CH (1990). Host responses to the pathogen. In: Fusarium wilt of banana (Ploetz RC, eds.). APS Press, American Phytopathological Society, St. Paul.

Castle A, Speranzini D, Rghei N, Alm G, et al. (1998). Morphological and molecular identification of Trichoderma isolates on North American mushroom farms. Appl. Environ. Microbiol. 64: 133-137.

Gautam SP, Bundela PS, Pandey AK, Jamaluddin, et al. (2012). Diversity of cellulolytic microbes and the biodegradation of municipal solid waste by a potential strain. Int. J. Microbiol. 2012:325907. http://dx.doi.org/10.1155/2012/325907

Ghose TK (1987). Measurement of cellulase activities. Pure Appl. Chem. 59: 257-268. http://dx.doi.org/10.1351/ pac198759020257

Genetics and Molecular Research 15 (4): gmr15048494 
Haygood RA and Strider DL (1982). A comparison of inoculation methods of Erwinia chrysanthemi in greenhouse ornamentals. Plant Dis. 66: 461-463. http://dx.doi.org/10.1094/PD-66-461

Huang YH, Wang RC, Li CH, Zuo CW, et al. (2012). Control of Fusarium wilt in banana with Chinese leek. Eur. J. Plant Pathol. 134: 87-95.http://dx.doi.org/10.1007/s10658-012-0024-3

Hwang SC and Ko WH (2004). Cavendish banana cultivars resistant to Fusarium wilt acquired through somaclonal variation in Taiwan. Plant Dis. 88: 580-588. http://dx.doi.org/10.1094/PDIS.2004.88.6.580

Jaklitsch WM, Samuels GJ, Ismaiel A and Voglmayr H (2013). Disentangling the Trichoderma viridescens complex. Persoonia 31: 112-146. http://dx.doi.org/10.3767/003158513X672234

Joshi BB, Bhatt RP and Bahukhandi D (2010). Antagonistic and plant growth activity of Trichoderma isolates of Western Himalayas. J. Environ. Biol. 31: 921-928.

Li CY, Chen S, Zuo CW, Sun QM, et al. (2011). The use of GFP-transformed isolates to study infection of banana with Fusarium oxysporum f. sp. cubense race 4. Eur. J. Plant Pathol. 131: 327-340. http://dx.doi.org/10.1007/s10658011-9811-5

Li CY, Deng GM, Yang J, Viljoen A, et al. (2012). Transcriptome profiling of resistant and susceptible Cavendish banana roots following inoculation with Fusarium oxysporum f. sp. cubense tropical race 4. BMC Genomics 13: 374. http:// dx.doi.org/10.1186/1471-2164-13-374

Miller GL (1959). Use of dinitrosalicylic acid reagent for determination of reducing sugar. Anal. Chem. 31: 426-428. http://dx.doi.org/10.1021/ac60147a030

Morton DJ and Stroube WH (1955). Antagonistic and stimulating effects of soil micro-organism of Sclerotium. Phytopathology 45: 417-420.

Mysore VT, Basavanna M, Monnanda SN, Harishchandra SP, et al. (2005). Endophytic fungal assemblages from inner and twig of Terminalia arjuna W. and A. (Combretaceae). World J. Microbiol. Biotechnol. 21: 1535-1540. http:// dx.doi.org/10.1007/s11274-005-7579-5

Ploetz RC (1990). Population biology of Fusarium oxysporum f. sp. cubense. In: Fusarium wilt of banana (Ploetz RC, eds.). APS Press, American Phytopathological Society, St. Paul.

Ploetz RC (1994). Panama disease: return of the first banana menace. Int. J. Pest Manage. 40: 326-336. http://dx.doi. org/10.1080/09670879409371908

Ploetz RC (2015). Fusarium wilt of banana. Phytopathology 105: 1512-1521. http://dx.doi.org/10.1094/PHYTO-04-150101-RVW

Pointing SB, Buswell JA, Jones EBG and Vrijmoed LLP (1999). Extracellular cellulolytic enzyme profiles of five lignicolous mangrove fungi. Mycol. Res. 103: 696-700. http://dx.doi.org/10.1017/S0953756298007655

Raza W, Ling N, Zhang R, Huang Q, et al. (2016). Success evaluation of the biological control of Fusarium wilts of cucumber, banana, and tomato since 2000 and future research strategies. Crit. Rev. Biotechnol. 26: 1-11. http:// dx.doi.org/10.3109/07388551.2015.1130683

Sivan A, Ucko O and Chet I (1987). Biological control of Fusarium crown rot of tomato by Trichoderma harzianum under field conditions. Plant Dis. 71: 587-592. http://dx.doi.org/10.1094/PD-71-0587

Sundaramoorthy S and Balabaskar P (2013). Biocontrol efficacy of Trichoderma spp. against wilt of tomato caused by Fusarium oxysporum f. sp. lycopersici. J. Appl. Biol. Biotechnol. 1: 36-40.

Tamura K, Stecher G, Peterson D, Filipski A, et al. (2013). MEGA6: Molecular Evolutionary Genetics Analysis version 6.0. Mol. Biol. Evol. 30: 2725-2729. http://dx.doi.org/10.1093/molbev/mst197

Waqas M, Khan AL, Kamran M, Hamayun M, et al. (2012). Endophytic fungi produce gibberellins and indoleacetic acid and promotes host-plant growth during stress. Molecules 17: 10754-10773. http://dx.doi.org/10.3390/ molecules 170910754

Zhang JD and Yang Q (2015). Optimization of solid-state fermentation conditions for Trichoderma harzianum using an orthogonal test. Genet. Mol. Res. 14: 1771-1781.http://dx.doi.org/10.4238/2015.March.13.4

Genetics and Molecular Research 15 (4): gmr15048494 